\title{
Suitability and preparation of obese patients for bariatric surgery
}

\section{Introduction}

Obesity, defined by a Body Mass Index (BMI) $\geq 30 \mathrm{~kg} / \mathrm{m}^{2}$, is the most prevalent metabolic disease worldwide and constitutes a major public health problem. ${ }^{1-4}$ Type 2 Diabetes (T2DM), Hypertension, Dyslipidemia, Stroke, Coronary Heart Disease (CHD), Obstructive Sleep Apnea (OSA), Obesity-Hypoventilation Syndrome (OHS), NonAlcoholic Fatty Liver Disease (NAFLD) or Non-Alcoholic Steato Hepatitis (NASH), Gallbladder Disease, Osteoarthritis, Infertility, Cancer, Psychological difficulties are frequent comorbidities in the obese population, which can be prevented or improved with weight loss. ${ }^{5-7}$

Bariatric surgery is the most effective treatment for morbid obesity, improving the overall quality of life, comorbidities and mortality. ${ }^{8,9}$ However, surgery is not recommended to allobese patients. ${ }^{5,6}$ The potential benefits, indications, risks, contraindications for bariatric surgery must be considered for each patient, and an extensive workup to assess the suitability and to prepare the surgical candidate must be provided by an experienced multidisciplinary team, which should involve endocrinologists, bariatric surgeons, nutritionists, psychologist and/or psychiatrist, specialized nurse, social worker, and occasionally other specialized physicians, such cardiologists, pneumologists or gastroenterologists. ${ }^{10,11}$

Suitable candidates for a bariatric surgery includes patients with $\mathrm{BMI} \geq 40 \mathrm{~kg} / \mathrm{m}^{2}$ without comorbid illness, or BMI between $35.0-39.9 \mathrm{~kg} /$ $\mathrm{m}^{2}$ with at least one obesity-related comorbidity, including T2DM, OSA, OHS, Pickwickian syndrome (combination of OSA and OHS), asthma, hypertension, dyslipidemia, NAFLD/NASH, pseudotumor cerebri, gastroesophageal reflux disease, venous stasis disease, severe urinary incontinence, debilitating osteoarthritis, impaired quality of life and disqualification for other surgeries due to obesity. ${ }^{5,6,11-13}$ Bariatric surgery has proven a remarkable positive effect in T2DM, leading to high rates of diabetes remission and reduction of diabetesrelated mortality. ${ }^{14}$

The International Diabetes Federation and some bariatric centres support the surgical indication for patients with BMI between 30.0$34.9 \mathrm{~kg} / \mathrm{m}^{2}$ and poorly-controlled T2DM. ${ }^{11,15}$ The surgical candidates must be motivated to lose weight and/or fail to achieve or maintain satisfactory weight loss with behavioural treatment (with or without pharmacotherapy). Moreover, surgical candidates must undergo a detailed psychosocial evaluation, and also demonstrate understanding about surgical procedures and commitment to the long-term followup plan. , $, 6,11-13^{-13}$

Patients with severe, untreated or active psychosis, major depression, binge-eating disorders, dependence of alcohol or drugs and those unable to comply with nutritional and lifestyle requirements after surgery are considered unsuitable for surgery. ${ }^{6,16,17}$ Bariatric surgery is contraindicated in case of severe cardiac disease, coagulopathies or other conditions carrying relevant surgical/anaesthetical risks or threatening life in short-term..$^{10,11,18}$ Some guidelines restrain bariatric surgery for patients up to 60years, ${ }^{6,10}$ although others established higher age-cutoffs at 65 -70years. ${ }^{8,11}$
Volume 2 Issue 4 - 2015

Pedro Marques
Department of Endocrinology, Instituto Portugues de Oncologia
de Lisboa, Portugal

Correspondence: Pedro Marques, Endocrinology Department, Instituto Portugues de Oncologia de Lisboa, Rua Professor Lima Basto, 1099-023, Lisboa, Portugal, Tel +35 I 21720043।/217200432, Fax +35। 217229880 , Email pedro.miguel.sousa.marques@gmail.com

Received: July 25, 2015 | Published: August 03, 2015

Data about regarding age as restrictive factor for surgery is conflicting: ${ }^{19-23}$ patients older than 55years were found to have increased risk for mortality, ${ }^{19}$ and DeMaria ${ }^{20}$ identified advanced age ( $\geq 45$ years) as a preoperative risk factor for morbidity and mortality following surgery; ${ }^{20,21}$ however, age was not find to be a relevant surgical risk factor in other series. ${ }^{22,23}$ Likely, clinical evaluation and individualized decisions, regardless the absolute or specific age, are more appropriate to select patients for surgery. ${ }^{18,24}$ Older patients should be extensively evaluated in terms of surgical risks, existence of comorbidities, life expectancy, benefits of weight loss and quality of life. ${ }^{8,24}$

A comprehensive assessment should be offered to every surgical candidate by an experienced multidisciplinary team in order to determine their surgical suitability and to optimize their preoperative status, and at same time to ensure that the patient is completely informed about the surgical procedure and postoperative program, required for a sustainable weight loss/maintenance. ${ }^{8,11}$

Presurgical psychological assessment may identify psychological/ psychiatric dysfunctions, such personality disorders, bipolar diseases, eating behaviour disorders, psychosis, depression, anxiety, which are common in obese individuals. ${ }^{16,25-27}$ Kalarchian et al. ${ }^{28}$ found that $66 \%$ of surgical candidates have at least one lifetime mental disorder, $38 \%$ met criteria for mental disorders preoperatively and $29 \%$ had more than one mental disorder. ${ }^{28}$ These assessments aim to define patient's suitability for surgery, preoperative management in cases that surgery is still an option, and to avoid postoperative psychiatric-related complications or psychiatric-related unsuccessful outcomes. ${ }^{16,27}$

Beyond diagnostic purposes, psychosocial assessment constitutes an opportunity to prepare patients by exploring their vulnerabilities and concerns, to give education, to guarantee an informed/consented decision and to optimize the postoperative outcomes. Education should approach the expectable surgical effects and results, to make sure that patients don't create false or unrealistic expectations, but also to establish/reinforce achievable goals and proper means to reach them. ${ }^{6,16,17,29}$

Preoperative psychological assessments usually involves a standardized questionnaire and an interview. ${ }^{30-33}$ They must explore 
behavioural patterns through the comprehension of previous weight loss attempts (queries about past treatments, reasons for failed attempts, patterns of weight loss/regain), eating habits (queries about binge-eating, overeating, night time eating, stress-related eating), physical activity (assess the ability to incorporate an exercise plan in the daily life; patient should be encouraged to begin physical exercise prior to surgery), past and current substance abuse (and in which circumstances).

Cognition, motivation and emotional aspects should be also explored: intelligence and knowledge should be assessed (the patient should understand the surgical procedure, risks, complications, and the postoperative behavioural changes; moreover, patients should be educated for obesity itself and weight loss benefits); patients should be trained to develop copying skills, to eliminate maladaptive behaviours. The patient's current life situation should be investigated too. Obtaining information about lifestyle, stressors, physical exercise, social supports, job type and hobbies may be useful. ${ }^{6,16,17,29,33}$

Besides psychosocial evaluation, a medical assessment should be performed, in order to assess comorbidities, reassure surgical appropriateness, optimize and prepare patients for surgery. Generally, every surgical candidate should undergo a low/very low calorie diet, and also be stimulated for physical activity, in order to promote preoperative weight loss. Then, some comorbidities such T2DM, hypertension, dyslipidemia, may ameliorate before surgery; liver volume may reduce, facilitating the surgical procedure and reducing postoperative complications; the postoperatively compliance and results may improve too..$^{11,14,34-37}$

Among morbid obese patients undergoing surgery, $10-20 \%$ has T2DM, and an additional $10-30 \%$ has reduced glucose tolerance. ${ }^{38}$ Preoperatively, obese patients with T2DM should intensify their glucose-monitoring and their glycemic control should be optimized (with diet, exercise and antidiabetic drugs). ${ }^{11,39}$ Preoperative caloric restriction and physical activity increase the insulin sensitivity, and consequently patients on glucose-lowering drugs (such sulphonylureas or insulin) may carry hypoglycaemia risk, so adjustments of hypoglycemic-drugs are normally required. If possible insulin secretagogues or insulin should be withdrawn or reduced. Normally, premix or rapid acting insulin should be reduced by $50 \%$, and NPH or long-acting insulin by $30 \%$, aiming for a plasma glucose between $110-140 \mathrm{mg} / \mathrm{dL}$; if glycemia is constantly $<90 \mathrm{mg} / \mathrm{dL}$ further reductions should be advised.

Other antidiabetic drugs (metformin, acarbose, glitazones, GLP-1 analogs, inhibitors of dipeptidyl peptidase 4) could be maintained until surgery. ${ }^{11,14}$ Elevated preoperative glycemias and $\mathrm{HbA} 1 \mathrm{C}$ is correlated with postoperative hyperglycemia, which in turn is associated with wound infections, acute renal failure and decreased T2DM remission rates. ${ }^{40}$ The recommended $\mathrm{HbA} 1 \mathrm{C}$ for T2DM patients before surgery ranges between $6.5-7.0 \%$, but more liberal targets for patients with advanced micro or macrovascular complications should be considered (7.0-8.0\%). ${ }^{11}$ The metabolic optimization involve also the preoperative control of dyslipidemia and hypertension, so reasonable aims for total cholesterol, LDL-cholesterol, triglycerides and blood pressure are $<155 \mathrm{mg} / \mathrm{dL},<77 \mathrm{mg} / \mathrm{dL},<195 \mathrm{mg} / \mathrm{dL}$ and $<135 / 85 \mathrm{mmHg}$, respectively. ${ }^{8,10}$

Cardiac assessment, beyond an electrocardiogram, should be determined on the basis of clinical history, physical examination and individual cardiovascular risk factors. Patients with significant cardiac risk or suspected/known heart disease should be seen preoperatively by a cardiologist, and might be considered for further non-invasive cardiac testing and/or eventually for angiography or coronary revascularization if necessary. ${ }^{11,41}$ Unstable or active cardiac conditions, such CHD, decompensate/severe heart failure, arrhythmias or valvular disease should be optimized preoperatively. In the presence of two cardiac conditions or three or more cardiovascular risk factors, the use of beta-blockers must be considered, aiming to reduce heart rate and prevent cardiac events. ${ }^{11,41-43}$

From the respiratory point of view, routine preoperative screening for OSA (with polysomnography, eventually together with other tests such spirometry, arterial blood gases) should be offered to obese surgical candidates, considering the high prevalence of OSA in this setting (up to 94\%), and the OSA-associated risks for adverse surgical outcomes. ${ }^{44-48}$ In case of OSA standard preoperative management with continuous positive airway pressure is recommended. ${ }^{11,48}$ Oxygen treatment is indicated in OHS, defined by hypercapnia during the awake period in absence of other reasons for hypoventilation such chest deformities or coexisting pulmonary or neurological diseases. ${ }^{49,50}$

All patients, independently of the existence of respiratory diseases, must stop smoking at least two months before surgery. ${ }^{49,51}$ Preoperatively, it is also important to evaluate their upper airway and determine the challenges for intubation, frequently seen in these patients due to restricted neck and jaw mobility and fat deposition in the neck, oropharynx and upper larynx. ${ }^{11,52}$

Before surgery, every patient should eliminate alcohol intake, and a comprehensive nutritional assessment (including micronutrients) should be done in every surgical candidate. Despite the increased food intake normally observed in these patients, the quality of their diet is often poor lacking in many nutritional elements such iron, folic acid, calcium or vitamins D, B12, E, C and D. Nutritional deficiencies are then common in obesity, and might be worsened postoperatively, hence their screening and correction with appropriate supplements/ food should be routinely done in every patient. ${ }^{11,53-56}$

Patients with gastrointestinal symptoms should be evaluated prior to surgery, with imaging studies such abdominal ultrasound and/or endoscopy. Routine screening for Helicobacter pyloriis not recommended, but it should be considered in case of significant dyspepsia and/or in endemic areas, and if positive should be treated before surgery, because of the risk of postoperative ulceration may decrease ${ }^{11,57,58}$ Despite the frequency of NAFLD or NASH in the obese population, a routine abdominal ultrasonography is not recommended in this setting before surgery, except in presence of related complaints or abnormal liver function tests. . $^{11,59,60}$

Patients with characteristic symptoms or relevant risk factors for gallstones (e.g. high fat diet, very elevated triglycerides, family history of gallstones), or known personal history of gallstones, should be evaluated with imaging studies and considered for cholecystectomy during the bariatric surgery. Routine prophylactic cholecystectomy in all obese patients undergoing bariatric remains controversial. ${ }^{6}$

Preoperatively, another important aspect to take in consideration is the risk stratification for venous thromboembolism, which should be estimated in every surgical candidate. Those patients identified as highrisk for pulmonary embolism (medical history of thromboembolism, venous stasis disease, inability to ambulate), must be considered for chemoprophylaxis with heparin. ${ }^{62,63}$

The oestrogen replacement should be discontinued at least 3 weeks before bariatric surgery in order to reduce postoperative thromboembolism risk. Women candidate for surgery should be counselled to avoid pregnancy in the preoperative period, and also for the next 12 to 18 months after bariatric surgery. ${ }^{11,64}$ 
Subclinical hypothyroidism is frequent in obese patients; however, routine preoperative thyroid function assessment is not recommended due to obesity condition itself, but patients at risk for thyroid dysfunction (e.g. previous radiotherapy, familiar history of thyroid diseases) should be screened. ${ }^{11,65-67}$ Prophylactic treatment for gout attacks should be considered for patients with gout history prior to surgery, because active weight loss is known to be an important risk factor for hyperuricemia and acute gout crisis. ${ }^{11,68}$

Bariatric surgery is the most effective treatment for morbid obesity, ameliorating several obesity-related comorbidities and reducing the overall mortality in this setting. Establishment of comprehensive programs from an experienced multidisciplinary team to assess the suitability of patients for bariatric surgery and to optimize their preoperative status is essential to guarantee successful surgical outcomes and to prevent perioperative and postoperative complications.

\section{Acknowledgements}

None.

\section{Conflict of interest}

Author declares that there is no conflict of interest.

\section{References}

1. Kelly T, Yang W, Chen CS, et al. Global burden of obesity in 2005 and projections to 2030. Int J Obes (Lond). 2008;32(9):1431-1437.

2. Ogden CL, Carroll MD, Kit BK, et al. Prevalence of obesity in the United States. NCHS Data Brief. 2012;82:1-8.

3. Flegal KM, Kit BK, Orpana H, et al. Association of all-cause mortality with overweight and obesity using standard body mass index categories: a systematic review and meta-analysis. JAMA. 2013;309(1):71-82.

4. James WP. The epidemiology of obesity: the size of the problem. J Intern Med. 2008;263(4):336-352.

5. Jensen MD, Ryan DH, Apovian CM, et al. 2013 AHA/ACC/TOS guideline for the management of overweight and obesity in adults: a report of the American College of Cardiology/American Heart Association Task Force on Practice Guidelines and The Obesity Society. Circulation. 2014;129(25):102-138.

6. Tsigos C, Hainer V, Basdevant A, et al. Management of obesity in adults: European Clinical Practice Guidelines. Obes Facts. 2008;1(2):106-116.

7. Boido A, Ceriani V, Cetta F, et al. Bariatric surgery and prevention of cardiovascular events and mortality in morbid obesity: mechanisms of action and choice of surgery. Nutr Metab Cardiovasc Dis. 2015;25(5):437-443.

8. Mancini MC. Bariatric surgery - an update for the endocrinologist. Arq Bras Endocrinol Metab. 2014;58(9):875-888.

9. Padwal R, Klarenbach S, Wiebe N, et al. Bariatric surgery: a systematic review and network meta-analysis of randomized trials. Obes Rev. 2011;12(8):602-621.

10. Fried M, Yumuk V, Oppert JM, et al. Interdisciplinary European guidelines on metabolic and bariatric surgery. Obes Surg. 2014;24(1):42-55.

11. Mechanick JI, Youdim A, Jones DB, et al. Clinical practice guidelines for the perioperative nutritional, metabolic, and nonsurgical support of the bariatric surgery patient - 2013 Update: cosponsored by American Association of Clinical Endocrinologists, The Obesity Society, and American Society for Metabolic \& Bariatric Surgery. Endocr Pract. 2013;19(2):337-372.
12. Fried M, Hainer V, Basdevant A, et al. Interdisciplinary European guidelines on surgery of severe obesity. Obes Facts. 2008;1(1):52-58.

13. The Nice Clinical Guideline 189. Obesity: identification, assessment and management of overweight and obesity in children, young people and adults. 2014

14. Thorell A, Toft EH. Treatment of diabetes prior and after bariatric surgery. J Diabetes Sci Technol. 2012;6(5):1226-1232.

15. Cummings DE, Cohen RV. Beyond BMI: the need for new guidelines governing the use of bariatric surgery and metabolic surgery. Lancet Diabetes Endocrinol. 2014;2(2):175-181.

16. Pataky Z, Carrard I, Golay A. Psychological factors and weight loss in bariatric surgery. Curr Opin Gastroenterol. 2011;27(2):167-173.

17. LeMont D, Moorehead MK, Parish MS, et al. Suggestions for the presurgical psychological assessment of bariatric surgery candidates. American Society for Bariatric Surgery. 2004.

18. Bult M, Dalen T, Muller A. Surgical treatment of obesity. Eur J Endocrinol. 2008;158:135-145.

19. Livingston EH, Huerta S, Arthur D, et al. Male gender is a predictor of morbidity and age a predictor of mortality for patients undergoing gastric bypass surgery. Ann Surg. 2002;236(5):576-582.

20. DeMaria EJ, Murr M, Byrne TK, et al. Validation of the obesity surgery mortality risk score in a multicenter study proves it stratifies mortality risk in patients undergoing gastric bypass for morbid obesity. Ann Surg. 2007;246(4):578-582.

21. DeMaria EJ, Portenier D, Wolfe L. Obesity surgery mortality risk score: proposal for a clinically useful score to predict mortality risk in patients undergoing gastric bypass. Surg Obes Relat Dis. 2007;3(2):134-140.

22. Dorman RB, Abraham A, Al-Refaie WB, et al. Bariatric surgery outcomes in elderly: an ACS NSQIP study. $J$ Gastrointest Surg. 2012;16(1):35-44.

23. Flum DR, Belle SH, King WC, et al. Perioperative safety in the Longitudinal Assessment of Bariatric Surgery. $N$ Engl $J$ Med. 2009;361(5):445-454.

24. Frattini F, Amico F, Lavazza M, et al. Standardizing or tailoring bariatric surgery. Obes Surg. 2015;25(1):133.

25. Greenberg I, Sogg S, M Perna F. Behavioral and psychological care in weight loss surgery: best practice update. Obesity (Silver Spring). 2009; 17(5):880-884.

26. Pull CB. Current psychological assessment practices in obesity surgery programs: what to assess and why. Curr Opin Psychiatry. 2010;23(1):30-36.

27. Abiles V, Rodriguez RS, Abiles J, et al. Psycological characteristics of morbidly obese candidates for bariatric surgery. Obes Surg. 2010;20(2):161-167.

28. Kalarchian MA, Marcus MD, Levine MD, et al. Psychiatric disorders among bariatric surgery candidates: relationship to obesity and functional health status. Am J Psychiatry. 2007;164(2):328-334.

29. Marcus MD, Kalarchian MA, Courcoulas AP. Psychiatric evaluation and follow-up of bariatric surgery patients. Am $J$ Psychiatry. 2009;166(3):285-291.

30. Cassin S, Sockalingam S, Hawa R, et al. Psychometric properties of the Patient Health Questionnaire (PHQ-9) as a depression screening tool for bariatric surgery candidates. Psychosomatics. 2013;54(4):352-358.

31. Sogg S, Mori DL. The Boston interview for gastric bypass: determining the psychosocial suitability of surgical candidates. Obes Surg. 2004;4(3):370-380. 
32. Sogg S, Mori DL. Revising the Boston interview: incorporating new knowledge and experience. Surg Obes Relat Dis. 2008;4(3):455-463.

33. Greenberg I. Psychological aspects of bariatric surgery. Nutr Clin Pract. 2003;18(2):124-130.

34. Colles SL, Dixon JB, Marks P, et al. Preoperative weight loss with a very-low-energy diet: quantitation of changes in liver and abdominal fat by serial imaging. Am J Clin Nutr. 2006;84(2):304-311.

35. Van Nieuwenhove Y, Dambrauskas Z, Campillo-Soto A, et al Preoperative very low-calorie diet and operative outcomes after laparoscopic gastric bypass: a randomized multicenter study. Arch Surg. 2011;146(11):1300-1305.

36. Pouwels S, Wit M, Teijink J, et al. Aspects of exercise before or after bariatric surgery: a systematic review. Obes Facts. 2015;8(2):132-146.

37. Bond D, Vithiananthan S, Thomas G, et al. Bari-active: a randomized controlled trial of a preoperative intervention to increase physical activity in bariatric surgery patients. Surg Obes Relat Dis. 2015;11(1):169-180.

38. Greenway SE, Greenway FL, Klein S. Effects of obesity surgery on noninsulin-dependent diabetes mellitus. Arch Surg. 2002;137(10):1109-1117.

39. Schernthaner G, Morton JM. Bariatric surgery in patients with morbid obesity and type 2 diabetes. Diabetes Care. 2008;31(2):297-302.

40. Perna M, Romagnuolo J, Morgan K, et al. Preoperative hemoglobin A1c and postoperative glucose control in outcomes after gastric bypass for obesity. Surg Obes Relat Dis. 2012;8(6):686-690.

41. Fleisher LA, Beckman JA, Brown KA, et al. ACC/AHA 2007 Guidelines on perioperative cardiovascular evaluation and care for noncardiac suergery: executive summary: a report of the American College of Cardiology/American Heart Association Task Force on practice guidelines. J Am Coll Cardiol. 2007;50(17):1707-1732.

42. Fleisher LA, Beckman JA, Brown KA, et al. ACCF/AHA focused update on perioperative beta blockade incorporated into the ACC/AHA 2007 guidelines on perioperative cardiovascular evaluation and care for noncardiac surgery. J Am Coll Cardiol. 2009;54(22):13-118.

43. Kwon S, Thompson R, Florence M, et al. B-blocker continuation after noncardiac surgery: a report from the surgical care and outcomes assessment program. Arch Surg. 2012;147(5):467-473.

44. Rasmussen JJ, Fuller WD, Ali MR. Sleep apnea syndrome is significantly under diagnosed in bariatric surgical patients. Surg Obes Relat Dis 2012;8(5):569-573.

45. Kolotkin RL, LaMonte MJ, Walker JM, et al. Predicting sleep apnea in bariatric surgery patients. Surg Obes Relat Dis. 2011;7(5):605-610.

46. Palla A1, Digiorgio M, Carpene N, et al. Sleep apnea in morbidly obese patients: prevalence and clinical predictivity. Respiration. 2009;78(2):134-140.

47. Dixon JB, Schachter LM, O'Brien PE. Predicting sleep apnea and excessive day sleeping in the severely obese: indications for polysomnography. Chest. 2003;123(4):1134-1141.

48. Fritscher LG1, Mottin CC, Canani S, et al. Obesity and obstructive sleep apnea-hypopnea syndrome: the impact of bariatric surgery. Obes Surg. 2007;17(1):95-99.

49. de Sousa AG, Cercato C, Mancini MC, et al. Obesity and obstructive sleep apnea-hypopnea syndrome. Obes Rev. 2008;9(4):340-354.

50. Budweiser S, Riedl SG, Jorres RA, et al. Mortality and prognostic factors in patients with obesity-hypoventilation syndrome undergoing noninvasive ventilation. J Intern Med. 2007;261(4):375-383.
51. Myers K, Hajek P, Hinds C, et al. Stopping smoking shortly before surgery and postoperative complications: a systematic review and metaanalysis. Arch Intern Med. 2011;171(1):983-989.

52. Lindauer B, Steurer MP, Muller MK, et al. Anesthetic management of patients undergoing bariatric surgery: two year experience in a single institution in Switzerland. BMC Anesthesiol. 2014;14:125.

53. Xanthakos SA. Nutritional deficiencies in obesity and after bariatric surgery. Pediatr Clin North Am. 2009;56(5):1105-1121.

54. Schweiger C, Weiss R, Berry E, et al. Nutritional deficiencies in bariatric surgery candidates. Obes Surg. 2010;20(2):193-197.

55. Ernst B1, Thurnheer M, Schmid SM, et al. Evidence for the necessity to systematically assess micronutrient status prior to bariatric surgery. Obes Surg. 2009;19(1):66-73.

56. Tosh SY, Zarshenas N, Jorgensen J. Prevalence of nutrient deficiencies in bariatric patients. Nutrition. 2006;25(11-12):1150-1156.

57. Schirmer B, Erenoglu C, Miller A. Flexible endoscopy in the management of patients undergoing Roux-en-Y gastric bypass. Obes Surg. 2002;12(5):634-638.

58. Gould J. Prevalence of Helicobacter pylori infection among patients undergoing bariatric surgery: a preliminary study. World J Surg. 2008;32(9):2026-2027.

59. Al Akwaa A, El Zubier A, Al Shehri M. Pattern of liver function tests in morbidly obese Saudi patients undergoing bariatric surgery. Saudi J Gastroenterol. 2011;17(4):252-255.

60. Bower G, Toma T, Harling L, et al. Bariatric surgery and nonalcoholic fatty liver disease: a Systematic Review of Liver Biochemistry and Histology. Obes Surg. 2015;25(12):2280-9.

61. Amstutz S1, Michel JM2, Kopp S3, et al. Potential Benefits of Prophylactic Cholecystectomy in Patients Undergoing Bariatric Bypass Surgery. Obes Surg Mar. 2015: 25.

62. Caruana JA, Anain PM, Pham DT. The pulmonary embolism risk score system reduces the incidence and mortality of pulmonary embolism after gastric bypass. Surgery. 2009;146(4):683-685.

63. Winegar DA, Sherif B, Pate V, et al. Venous thromboembolism after bariatric surgery performed by Bariatric Surgery Center of Excellence Participants: analysis of the Bariatric Outcomes Longitudinal Database. Surg Obes Relat Dis. 2011;7(2):181-188.

64. Guelinckx I, Devlieger R, Vansant G. Reproductive outcome after bariatric surgery: a critical review. Hum Reprod Update. 2009;15(2):189-201.

65. Moulin de Moraes CM, Mancini MC, de Melo ME, et al. Prevalence of subclinical hypothyroidism in a morbidly obese population and improvement after weight loss induced by Roux-en-Y gastric bypass. Obes Surg. 2005;15(9):1287-1291.

66. Fierabracci P, Pinchera A, Martinelli S, et al. Prevalence of endocrine diseases in morbidly obese patients scheduled for bariatric surgery: beyond diabetes. Obes Surg. 2011;21(1):54-60.

67. Garber JR1, Cobin RH, Gharib H, et al. Clinical practice guidelines for hypothyroidism in adults: cosponsored by American Association of Clinical Endocrinologists and the American Thyroid Association. Endocr Pract. 2012;18(6):988-1028.

68. Friedman JE, Dallal RM, Lord JL. Gouty attacks occur frequently in postoperative gastric bypass patients. Surg Obes Relat Dis. 2008;4(1):11-13 